Research Article

\title{
THE EFFECT OF GRAPHENE OXIDE ON THE STRUCTURAL AND ELECTRICAL PROPERTIES OF YTTRIUM FERRITE BASED NANOPOWDERS
}

\begin{abstract}
Handan AYDIN
In this study, Yttrium Ferrite based nano electroceramics were prepared by the doping at various ratios of graphene oxide by the hydrothermal method. The obtained doped and undoped samples were characterized by XRD, SEM, FTIR, DTA, UV-VIS-NIR spectroscopy, temperature dependent electrical resistance changes and dielectric measurements. From the XRD results, it is observed that the obtained samples are polycrystalline with an Orthorhombic structure. The crystal parameters are changed with the doping of graphene oxide. FTIR spectra indicate that the graphene oxide changes the peak intensities. This confirms the incorporation of the graphene oxide into the ceramic structure. The doping of the graphene oxide changes the optical band gaps of the samples. The dielectric constants of the samples are changed with the graphene oxide. The DC electrical conductivity measurements confirm the semiconducting behavior of the samples. The obtained results indicate that the electronic and nanostructure of the synthesized electroceramics can be controlled by the doping of graphene oxide for electronic and energy applications.
\end{abstract}

Keywords: Hydrothermal method, Graphene oxide, Hummers method, Nano electroceramic, structural properties.

\section{Introduction}

Over the last years, research on the nano-structured electroceramics has been increasing. These materials have played an important role in advanced technology applications [1] such microwave industries [2], electronics [2], data storage devices [2, 3], gas-sensitive sensors [4], digital disk recording[2] and actuator applications [2]. Efforts have been made for the improving of specific properties and potential applications [5] of nano electroceramics $\mathrm{ABO}_{3}$ type (where $\mathrm{A}$ is a rare or alkaline earth metal and $\mathrm{B}$ is a first-row transition metal) [6, 7]. The materials in this formula are often referred to as rare earth orthoferrites [8]. Orthoferrites have attracted attention due to their a wide range of Ferro-, piezo-, pyroelectrical properties and electro-optical effects[7]. Yttrium ferrite $\left(\mathrm{YFeO}_{3}\right)$ is a member of this class. It has perovskite structure with an orthorhombic unit cell $[5,8,9]$ and a p-type semiconductor $\left(E_{g}=2.58 \mathrm{eV}\right)[4]$.

Recently, the studies on the structural and electrical properties of yttrium ferrite are increasing. In this context, the scientists have investigated and concentrated zoom in on improving the properties of Yttrium Ferrite with a different dopant and various element.

Handan AYDIN, Department of Metallurgy and Materials Engineering, Engineering Faculty, University of Munzur, Tunceli, TR, (handanaydin23@gmail.com) @https://orcid.org/0000-0002-0141-9773 
In recent years, to produce these materials have been used different synthesis process such as solvothermal [2], sol-gel [2, 5, 6, 8-11], , hydrothermal method [6, 8, 9], coprecipitation [8, 9], solid state reaction method $[5,6,9,10]$, self-propagating combustion synthesis [5], alkoxide method [5, 10], , pulsed laser deposition [5, 10], microwave-assisted [5, 9, 10], sonochemical synthesis [2, 5, 10]. Among these production methods, hydrothermal synthesis can be preferred due to its advantages such low temperature, control of particle size, without any calcination or milling step and not purity phase [12]. In this scientific study, pure and Graphene oxide doped Yttrium Ferrite nano electro-ceramics were synthesized by the Hydrothermal Process. The structural, morphological, chemical and physical electrical properties of the obtained samples were investigated.

\section{Experimental Details}

\subsection{Synthesis of Graphene Oxide}

Graphene oxide was prepared by a modified Hummers method. In this method, $1 \mathrm{~g}$ graphite powder, $0.5 \mathrm{~g}$ sodium nitrate and $23 \mathrm{ml}$ sulfuric acid were mixed into a beaker and exposed stirring for $30 \mathrm{~min}$ in an ice bath. Then $3 \mathrm{~g}$ potassium permanganate was slowly added to mixture solution by magnetic stirring through 6 hours. Subsequently, after the solution was kept in the ultrasonic machine for 2 hours and $100 \mathrm{ml}$ distilled water and $2 \mathrm{ml} \mathrm{H}_{2} \mathrm{O}_{2}(30 \%)$ were added by using a magnetic stirrer. Finally, the solution was washed with de-ionized water and filtered until $\mathrm{pH}$ value reached to 7.

\subsection{Synthesis of $\mathrm{YFeO3}$ via Hydrothermal Method}

Synthesis of $\mathrm{YFeO}_{3}$ nano electroceramics were carried out by hydrothermal route. The precursor solution was prepared using Yttrium (III) nitrate hexahydrate ( $\mathrm{N}_{3} \mathrm{O}_{9} \mathrm{Y}$ ) (Abcr, \%99,9), Iron (III) Chloride Hexahydrate $\left(\mathrm{FeCl}_{3} .6 \mathrm{H}_{2} \mathrm{O}\right)$ (Merck, \%99) and potassium hydroxide $(\mathrm{KOH})($ Merck, \%85) as mineralizer and de-ionized water as a reaction medium. For the production process of the samples, the schematic diagram about with Hydrothermal method is given in Fig. 1. In this reaction procedure, four solutions containing $\mathrm{N}_{3} \mathrm{O}_{9} \mathrm{Y}, 5.5 \mathrm{mmol} \mathrm{FeCl}_{3} .6 \mathrm{H}_{2} \mathrm{O}$, and 9 mol $\mathrm{KOH}$ were prepared. $6.1 \mathrm{mmol}$ of $\mathrm{N}_{3} \mathrm{O}_{9} \mathrm{Y}$ was added into $55 \mathrm{~mL}$ of de-ionized water with constant magnetic stirring followed by the addition of 6.1 mmol of $\mathrm{FeCl}_{3} .6 \mathrm{H}_{2} \mathrm{O}$. The solutions were stirred at room temperature for $1 \mathrm{~h}$ to obtain a homogeneous solution. Thereafter, $\mathrm{KOH}$ was slowly added to the above Y-Fe solution to co-precipitate. The solution was kept at room temperature ${ }^{\circ} \mathrm{C}$ for $2 \mathrm{~h}$ under stirring. After, each graphene oxide solution was added to the precursor solution. The final mixture is here after called LFO, LFO20, LFO50 and LFO100, respectively. The suspension solution was poured into full-automatically hydrothermal system (Fytronix HT-100) for the hydrothermal process. The process was carried out for $6 \mathrm{~h}$ at temperature of $200{ }^{\circ} \mathrm{C}$. After completion of the hydrothermal reaction, the autoclave was cooled naturally to the room temperature. The products were filtered and dried at room temperature for $24 \mathrm{~h}$. The obtained powders were formed by hydraulic press machine under a uniaxial pressure of $10 \mathrm{MPa}$ at room temperature.

\subsection{Characterization of Samples}

The crystalline phase of the products was recognized using a BRUKER ADVANCE D8 X-ray diffractometer with $\mathrm{Cu} \mathrm{K \alpha}$ radiation ( $\lambda=1.5406 \AA$ ) in the $2 \theta$ range from 20 to $80^{\circ}$ with $0.02 \% \mathrm{~min}$. at room temperature. The morphology of nano electro-ceramics were investigated with the a HighResolution Scanning electron microscope (JEOL JSM-7001F). High-Resolution Transmission electron microscope (JEOL JEM-2100F) was performed at an accelerating voltage of $200 \mathrm{kV}$, by placing the powder on a copper grid to observe the microstructure of the powders. The optical spectrum was recorded by a SHIMADZU 3600 UV-VIS-NIR spectrophotometer in the wavelength range of 200-1400 
$\mathrm{nm}$ at room temperature. The thermal analysis of the powders were determined by SHIMADZU DTG$60 \mathrm{AH}$ from room temperature to $900{ }^{\circ} \mathrm{C}$ in Argon ambient at a scan rate of $10{ }^{\circ} \mathrm{C} / \mathrm{min}$. FTIR spectra studies were made with Thermo Scientific Nicolet IS5 mark Fourier transform infrared spectrometer with an ID5 ATR sample holder in the wavenumber range from 400 to $4000 \mathrm{~cm}-1$. The dielectric and alternating current conductivity properties were investigated using a HIOKI 3532-50 LCR HITESTER at room temperature. The ferroelectric properties were studied using Radiant Precision Premier II Technology. The electrical conductivity of the samples was measured as a function of temperature using a KEITHLEY 6517A electrometer.

\section{Results and Discussion}

\subsection{Structural and morphological characterization of Producted Nano Electroceramics}

The XRD patterns of pure and $\mathrm{GO}$ doped $\mathrm{YFeO}_{3}$ nanostructure powder samples are shown in Fig.1. The observed all peaks in Fig.1. revealed that $\mathrm{YFeO} 3$ are polycrystalline structure with the orthorhombic structure. The crystalline phases were identified by reference to the Joint Committee on Powder Diffraction Standards (JCPDS 01-073-1345) files. XRD pattern of the samples were appeared at $2 \theta$ values, $33.462^{\circ}, 35.956^{\circ}$ and $54.361^{\circ}$ corresponding to (200), (120) and (310) reflections, respectively. As seen in the XRD peaks, the intensity of peaks is changed with increasing Graphene oxide doping. This indicates that Graphene oxide is incorporated into sites of $\mathrm{YFeO}_{3}$.

The lattice parameters ( $a, b$ and $c$ ) of the orthorhombic perovskite structure of $\mathrm{YFeO}_{3}$ at various graphene oxide contain were determined according to the following relations $[6,13,30]$ :

$$
\frac{1}{d_{h k l}{ }^{2}}=\frac{h^{2}}{a^{2}}+\frac{k^{2}}{b^{2}}+\frac{l^{2}}{c^{2}}
$$

Where $(h, k, 1)$ are the indices of every peak of crystallographic plane obtained from XRD patterns. $d$ is the interplanar distance, $(a, b, c)$ are the lattice constants. Average crystallite sizes were estimated using the Debye-Scherrer equation [1, 14-19,31]:

$$
D=\frac{0.9 \lambda}{\beta \cdot \cos \theta}
$$

The crystallite parameters of the unit cells of the samples are given in Table 1. As seen in Table 1 , with the addition of graphene oxide, the crystallite size was changed for (200) crystal plane.

Table 1. The calculated values of the crystallite parameters of the unit cells of the samples.

\begin{tabular}{cccccc}
\hline \hline & $\mathbf{2} \boldsymbol{\theta}\left({ }^{\circ}\right)$ & Crystal Structure & FWHM & Crystallite Size $(\mathbf{n m})$ & $\mathbf{d}(\mathbf{n m})$ \\
\hline YFO & 33,462 & Orthorhombic & 0,304 & 27,30 & 0,2675 \\
YFO20 & 33,484 & Orthorhombic & 0,330 & 25,15 & 0,2674 \\
YFO50 & 33,312 & Orthorhombic & 0,225 & 36,87 & 0,2687 \\
YFO100 & 33,352 & Orthorhombic & 0,209 & 39,69 & 0,2684 \\
\hline \hline
\end{tabular}




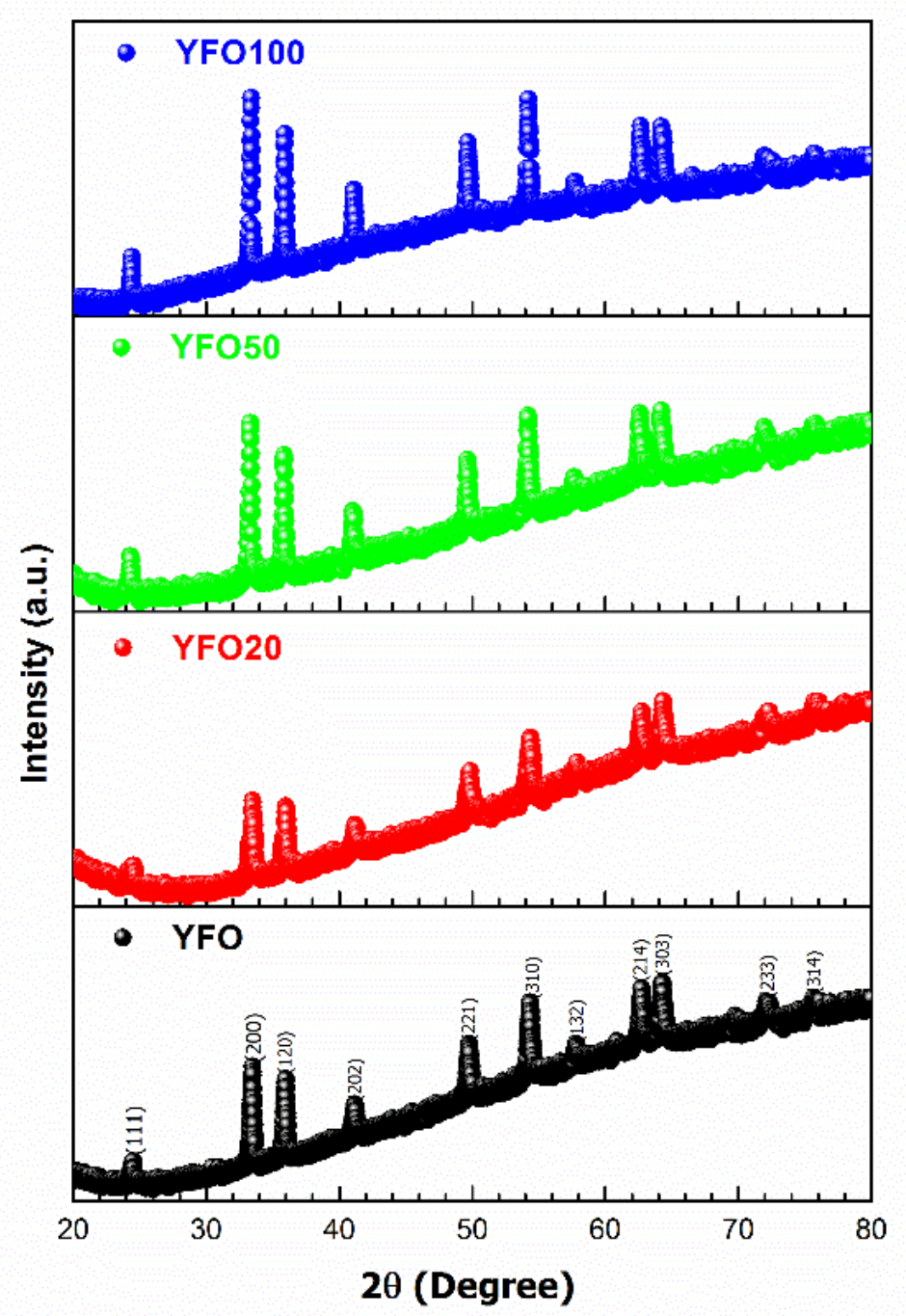

Figure 1. XRD spectrum of Samples

In order to determine the surface morphologies of undoped and graphene oxide-doped $\mathrm{YFeO}_{3}$ samples prepared by using the hydrothermal method they were analyzed with Scanning Electron Microscope (SEM). Fig.2. shows SEM images of the prepared samples. When the SEM images in Fig.2. were examined, it was seen that the grains on the surface of the sample were large and small, were randomly oriented, and were not distributed homogeneously and there were partial accumulations formed by grain stacks. It could be clearly seen that the samples formed in composite structure made of nano-sized grains and there were morphological differences in surface structure. The surface structure of the samples was generally composed of grains with similar size and morphology. It was very obvious that the surface morphologies of the samples changed with the graphene oxide dopant [32]. The change of crystallite size and particle size with the amount of graphene oxide ara portrated in Fig.3. 

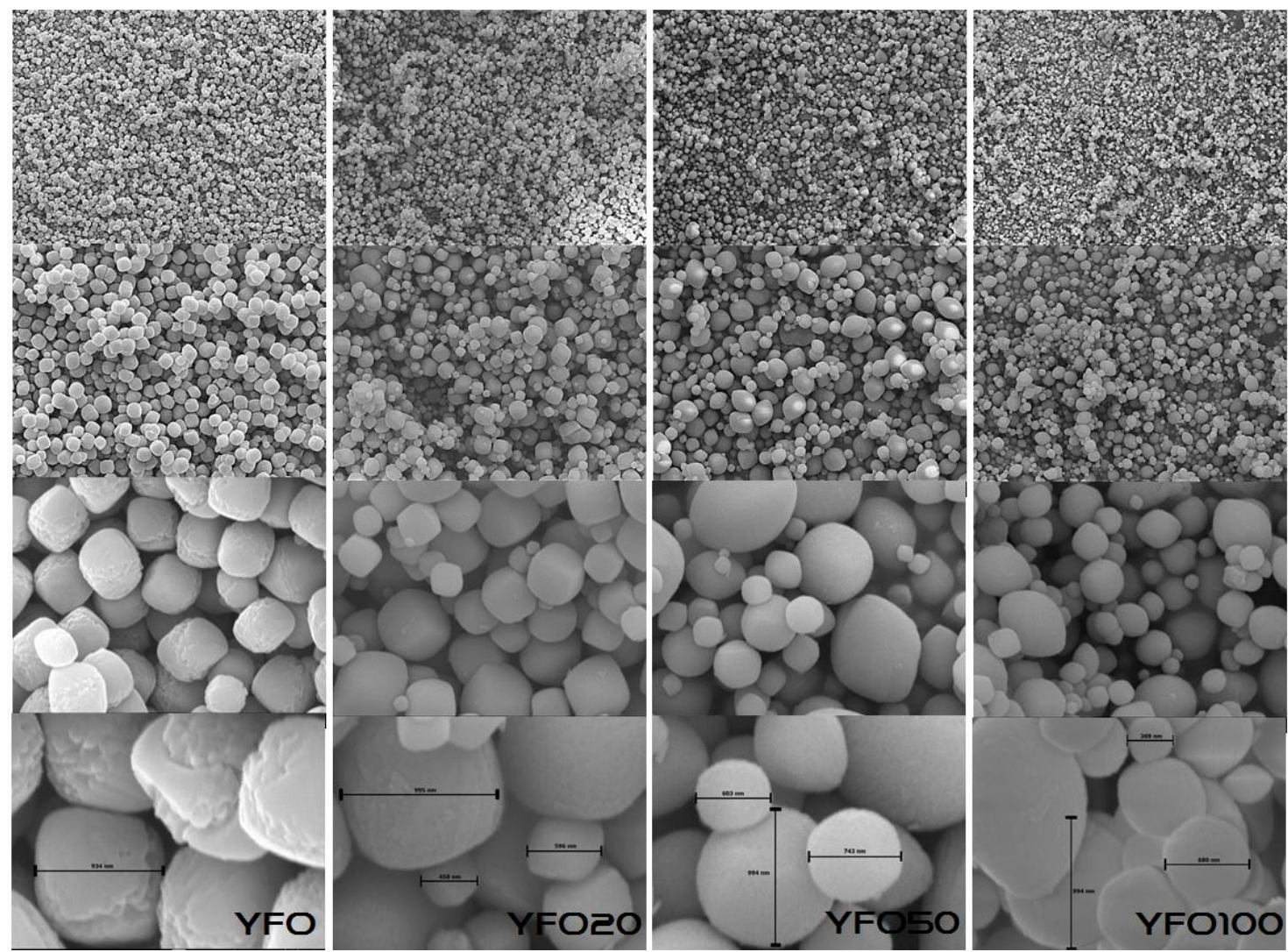

Figure 2. Scanning Electron Microscopy photographs of the Yttrium Ferrite nanopowders

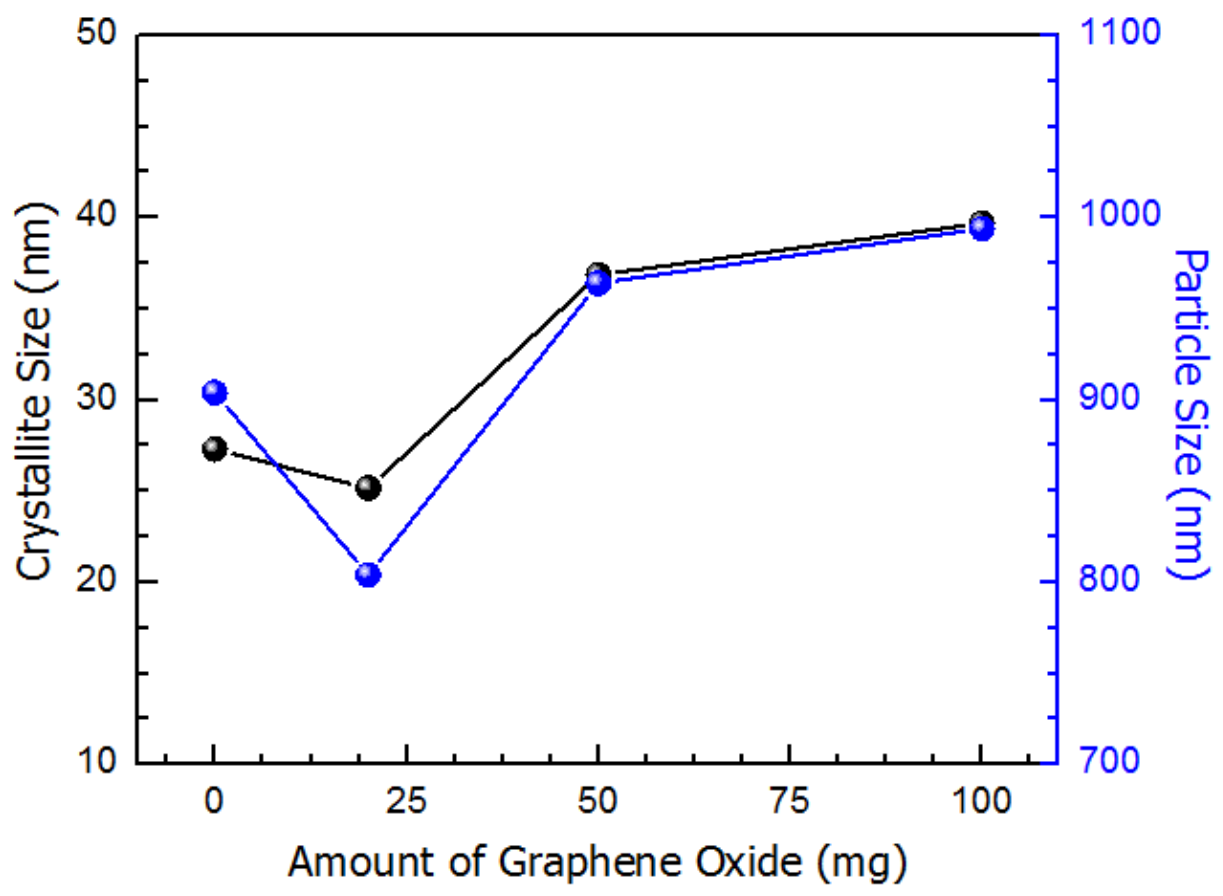

Figure 3. The change of crystallite size and particle size with the amount of graphene oxide 


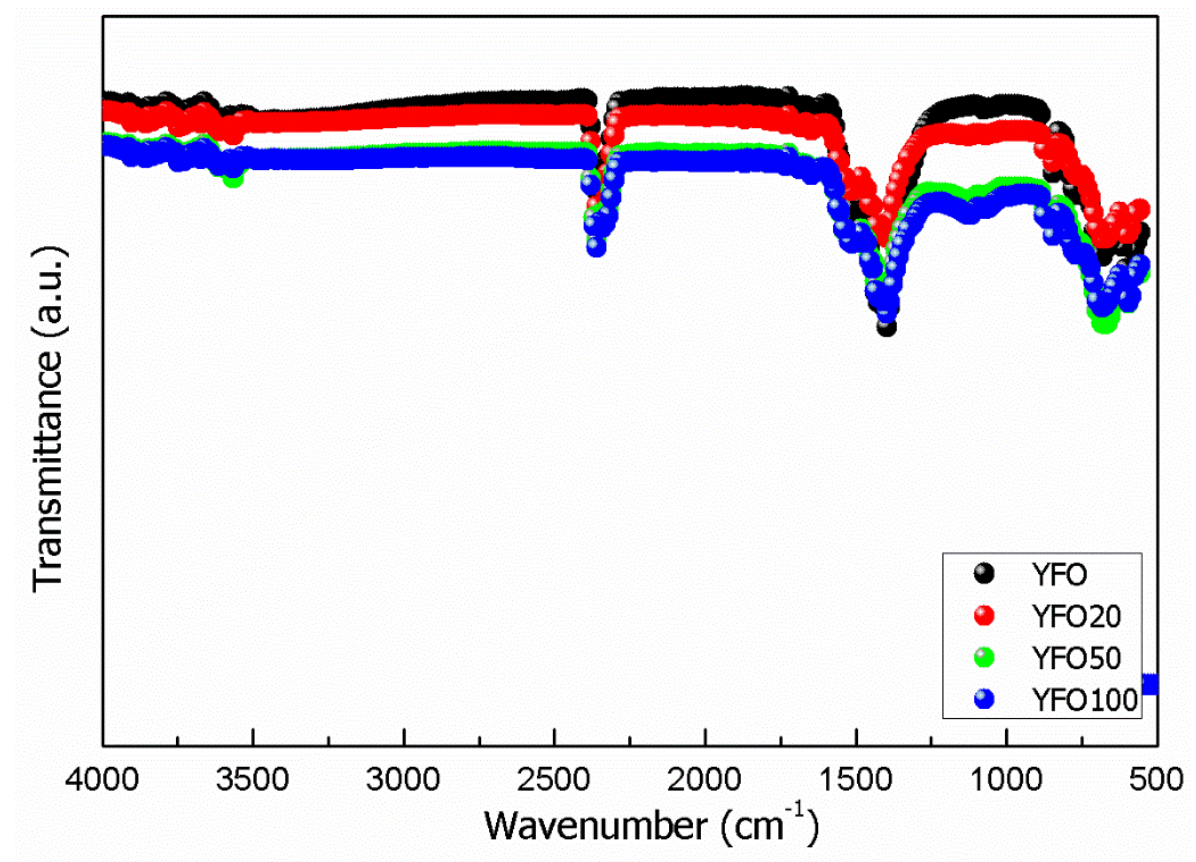

Figure 4 FT-IR spectra of synthesized yttrium ferrite nano powders

The FTIR spectra of the samples are shown in Fig. 4., and the as-detected bands can be explained as follows. The band detected at $1507 \mathrm{~cm}^{-1}$ is attributed to the bending mode of $\mathrm{H}_{2} \mathrm{O}$ band. The characteristic band of $\mathrm{CO}_{2}$ is detected at $2364 \mathrm{~cm}^{-1}$. The band at $1397 \mathrm{~cm}^{-1}$ is due to the $\mathrm{C}=\mathrm{O}$ bond. The band observed at $1320-1360 \mathrm{~cm}^{-1}$ is related to the $\mathrm{NO}^{-}$stress vibration mode. The band at $592 \mathrm{~cm}^{-1}$ is related to the bending vibration mode of $\mathrm{Fe}-\mathrm{O}$ bond.

Fig. 5. shows both DTA curves in the range from room temperature to $900{ }^{\circ} \mathrm{C}$ for each sample. There are one exothermic peaks in the DTA thermograms of all the samples. At the temperatures below the this peak, the weight losses are due to the elimination of the adsorbed water from the samples.

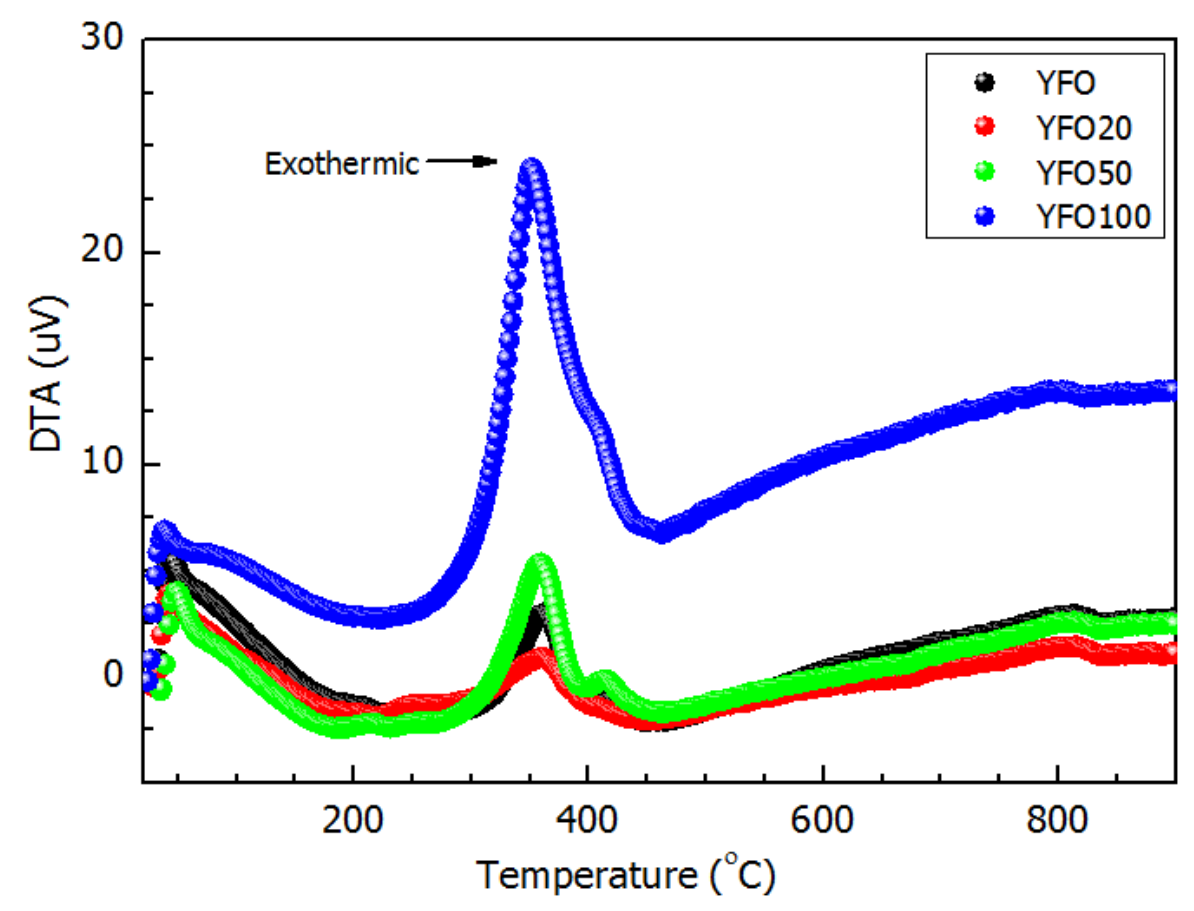

Figure 5. DTA curves for the nanopowders 
For the peaks for each sample, these losses may be due to the elimination of some oxygencontaining functional groups. While the peak is detected at $358,352,355$ and $348{ }^{\circ} \mathrm{C}$ for YFO, YFO20, YFO and YFO100, respectively. As can be easily seen from DTA thermograms, these peaks detected at the above-mentioned temperatures are due to the weight loss for each sample. These findings mean that the amount of the additive affects significantly the thermal stability of the GO.

\subsection{Optical characterization}

Reflection spectra of undoped and graphene oxide doped $\mathrm{YFeO}_{3}$ samples are presented in Fig. 6. As shown in Fig. 6, the reflection curves of the samples show a rapid decrease in a wavelength of about $600 \mathrm{~nm}$. This peak varies depending on graphene oxide adding. This confirms that the optical band gaps of the films change with graphene oxide doping. With graphene oxide doping, the reflectance values of the samples increase compared to the undoped $\mathrm{YFeO}_{3}$ sample. The change in optical reflectance may be due to the morphological change in the samples because the aspect ratio of the crystallites varies depending on the sample surfaces. The results obtained confirm the results obtained in the SEM photographs. The sample with the highest reflectance value is the undoped YFO50 sample. Besides, the reflectance values decreased at shorter wavelengths. The reason for this may be the reflection of photons due to the decrease in their energy and thus less interaction with electrons, atoms, or crystal molecules.

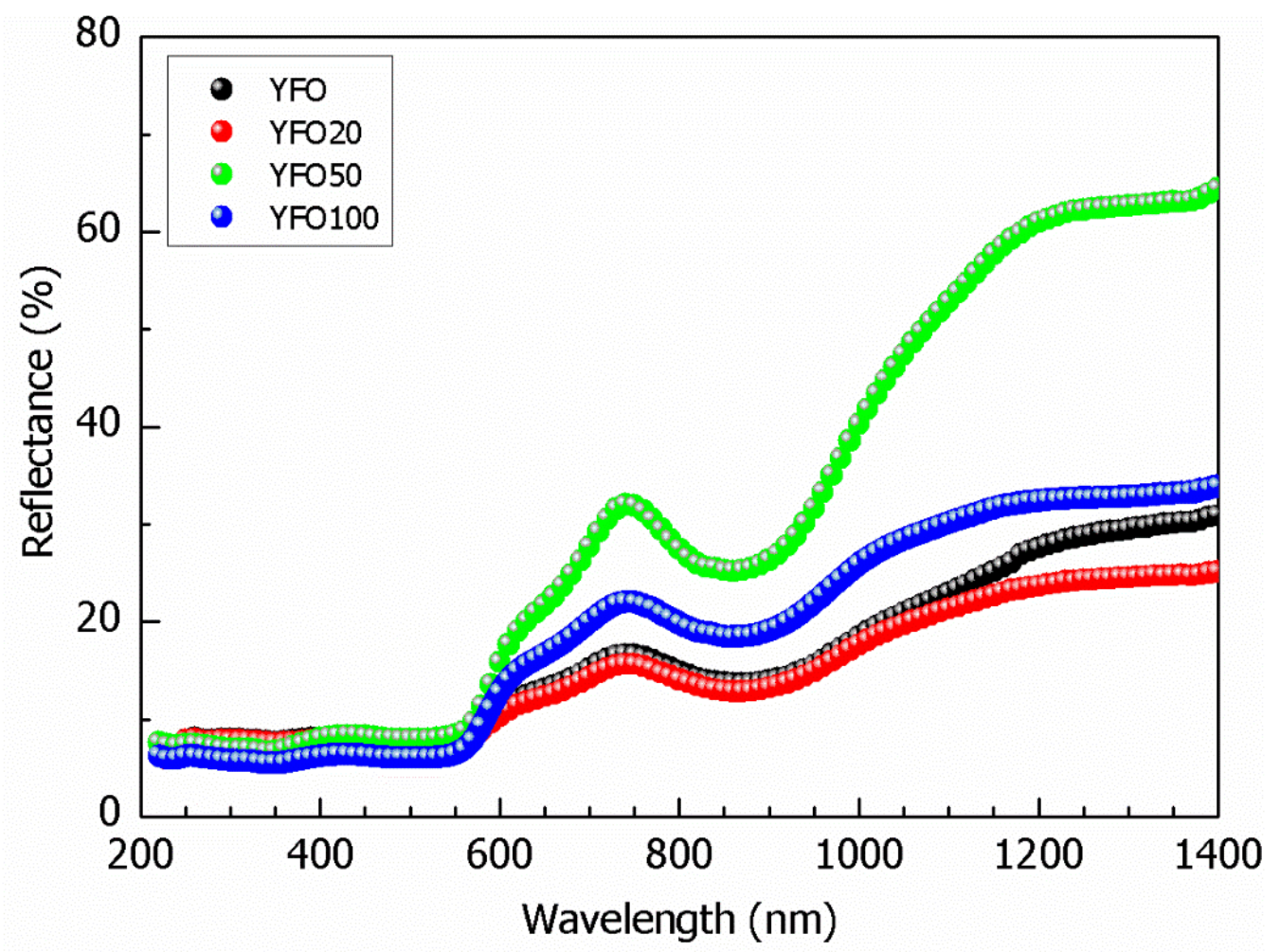

Figure 6. The reflectance spectra of samples as a function of wavelength

The optical band gap $\left(E_{g}\right)$ had a direct effect on the optical properties of the semi-conductive samples. The diffuse reflectance spectra given in the Fig. 6. were used to determine the band gaps (Eg) of the undoped and graphene oxide doped $\mathrm{YFeO}_{3}$ nano powders by using the Kubelka-Munk function. Kubelka-Munk function [18] can be defined as follows [1, 13, 16, 17, 19-24,33-35] : 


$$
\left(\frac{F(R) h v}{t}\right)=A \cdot\left(h v-E_{g}\right)^{n}
$$

Where $R$ is diffuse reflectance; $\mathrm{F}(\mathrm{R})$ is Kubelka-Munk function corresponding to the absorption value; $t$ is the thickness of the sample; $\mathrm{A}$ is an energy-independent constant, $h v$ is photon energy, and $\mathrm{E}_{\mathrm{g}}$ is band gap and $\mathrm{n}$ is $1 / 2$ for direct transitions.

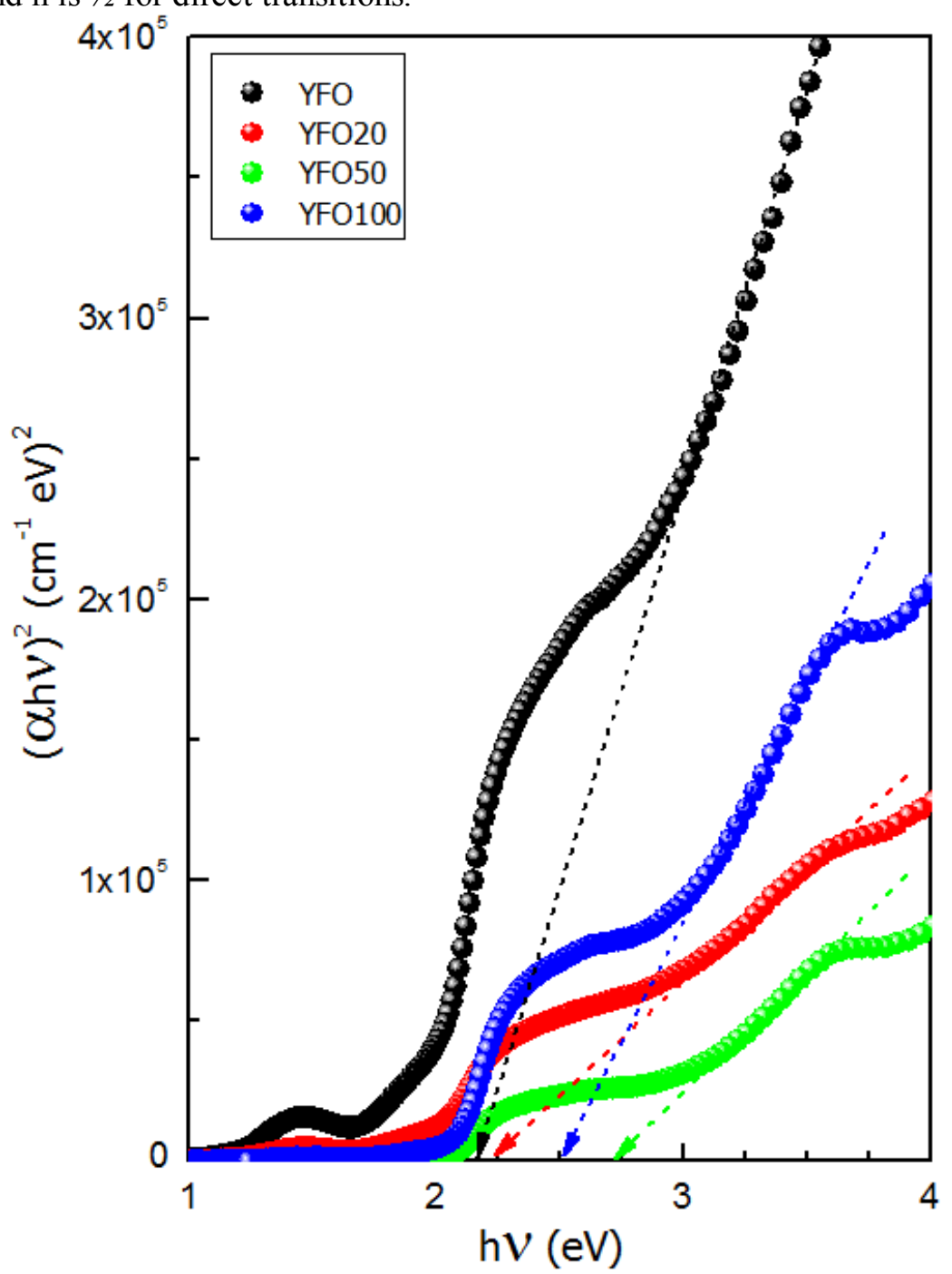

Figure 7. The plot of Kubelka-Munk relation for the yttrium ferrite nano electroceramics

The $h v-(\alpha h v)^{2}$ graphs of the samples were drawn and the point where the line opposite to the linear part of the graph intersected the axis $h v$ at 0 was determined. Fig.7. shows the $h v-(\alpha h v)^{2}$ graphs of the samples. The values of the band gap $\left(\mathrm{E}_{\mathrm{g}}\right)$ calculated with the help of these curves were shown in the Table 2. As can be seen from the Table 2, $\mathrm{E}_{\mathrm{g}}$ values of the samples increased as the atomic rate of the doped Fe increased. The reason of the increase in the band gaps of the samples was the increase in the crystal size. Since the optical properties are were affected by the changes in the size of the nanostructure. The change in the band gap with the doping process is known as "Burstein-Moss" effect. The energy band gap is in the visible region and hence the $\mathrm{YFeO} 3$ nanopowders in the current study are a good candidate for optical applications[25]. The variation of band gap and actiavtion energy with the amount of graphene oxide are presented in Fig. 8. 
Table 2. Optical band gap $\left(E_{g}\right)$ and the activation energy $\left(\Delta E_{A}\right)$ of the nanopowders

\begin{tabular}{cccc}
\hline \hline & $\boldsymbol{E}_{\boldsymbol{g}}(\mathbf{e V})$ & Activation Energy $\left(\Delta \boldsymbol{E}_{\boldsymbol{A}}\right)(\mathbf{e V})$ & $\boldsymbol{\sigma d c}(\mathbf{S} / \mathbf{c m})\left(\mathbf{3 0}{ }^{\circ} \mathbf{C}\right)$ \\
\hline YF0 & 2,20 & 0,796 & $1,09 \times 10^{-6}$ \\
YFO20 & 2,13 & 0,651 & $4,11 \times 10^{-7}$ \\
YFO50 & 2,66 & 0,606 & $3,53 \times 10^{-6}$ \\
\hline YFO100 & 2,50 & 0,337 & $1,16 \times 10^{-6}$ \\
\hline \hline
\end{tabular}

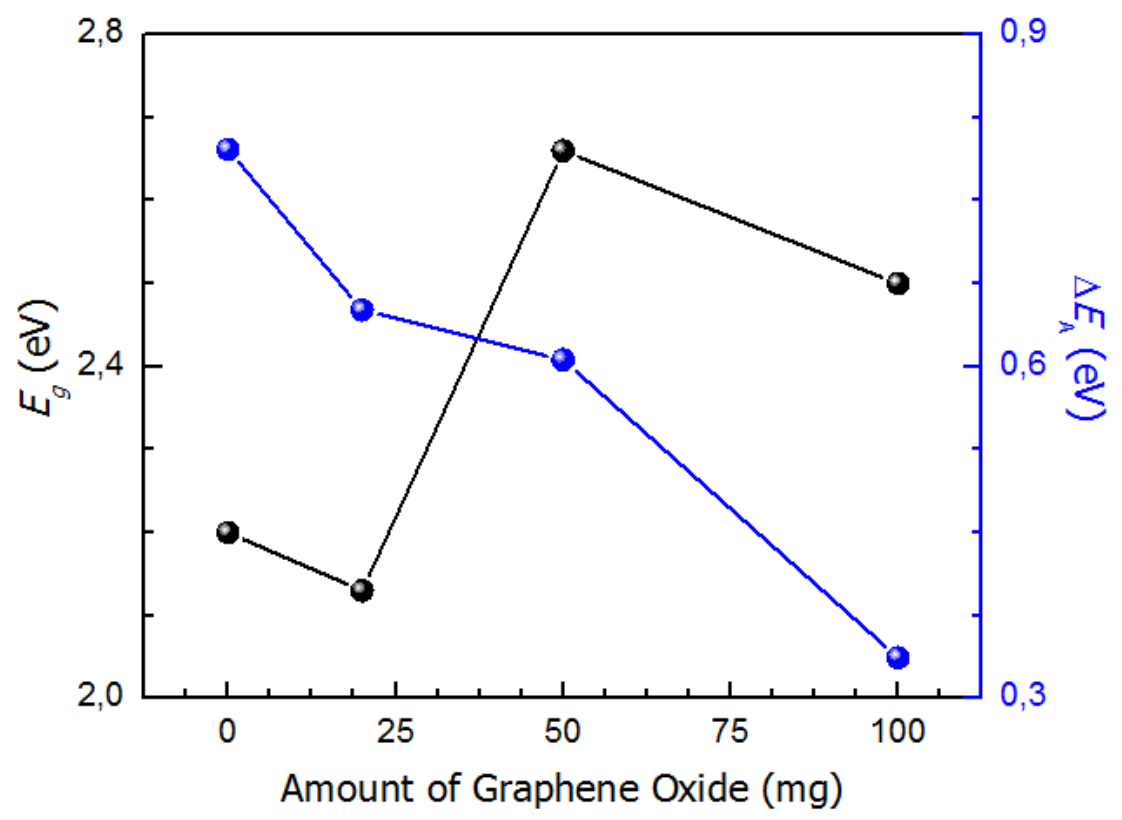

Figure 8. The variation of band gap and actiavtion energy with the amount of graphene oxide

\subsection{Electrical characterization}

The dielectric properties of the $\mathrm{YFeO}_{3}$ samples were investigated in the frequency range from 1 $\mathrm{kHz}$ to $5 \mathrm{MHz}$. The relative permittivity $\left(\varepsilon^{\prime}\right)$, dielectric loss $\left(\varepsilon^{\prime \prime}\right)$ and alternating current conductivity (бac) were calculated using the following relations, respectively

The relative permittivity $\left(\varepsilon^{\prime}\right)$, dielectric loss $\left(\varepsilon^{\prime \prime}\right)$ and alternating current conductivity ( $\left.\sigma a c\right)$ values of the samples were determined by the following relations $[26,27,36]$ :

$$
\begin{gathered}
\varepsilon^{\prime}=\frac{C_{p} \cdot t}{\varepsilon_{0} \cdot A} \\
\varepsilon^{\prime \prime}=\tan \delta \cdot \varepsilon^{\prime} \\
\sigma_{a c}=\frac{l}{Z \cdot A}
\end{gathered}
$$

where $\varepsilon_{0}$ is the permittivity of free space, $A$ is the area of the electrode, $C$ is the capacitance, $l$ is the thickness of the sample, $\tan \delta$ is the loss tangent and $Z$ is the impedance. Using the equations from 2 to 4 , the relative permittivity $\left(\varepsilon^{\prime}\right)$, dielectric loss $\left(\varepsilon^{\prime \prime}\right)$ and alternating current conductivity $\left(\sigma_{a c}\right)$ values were computed and their changes with increasing frequency were also plotted in Figs. 9, 10 and 11, respectively. 


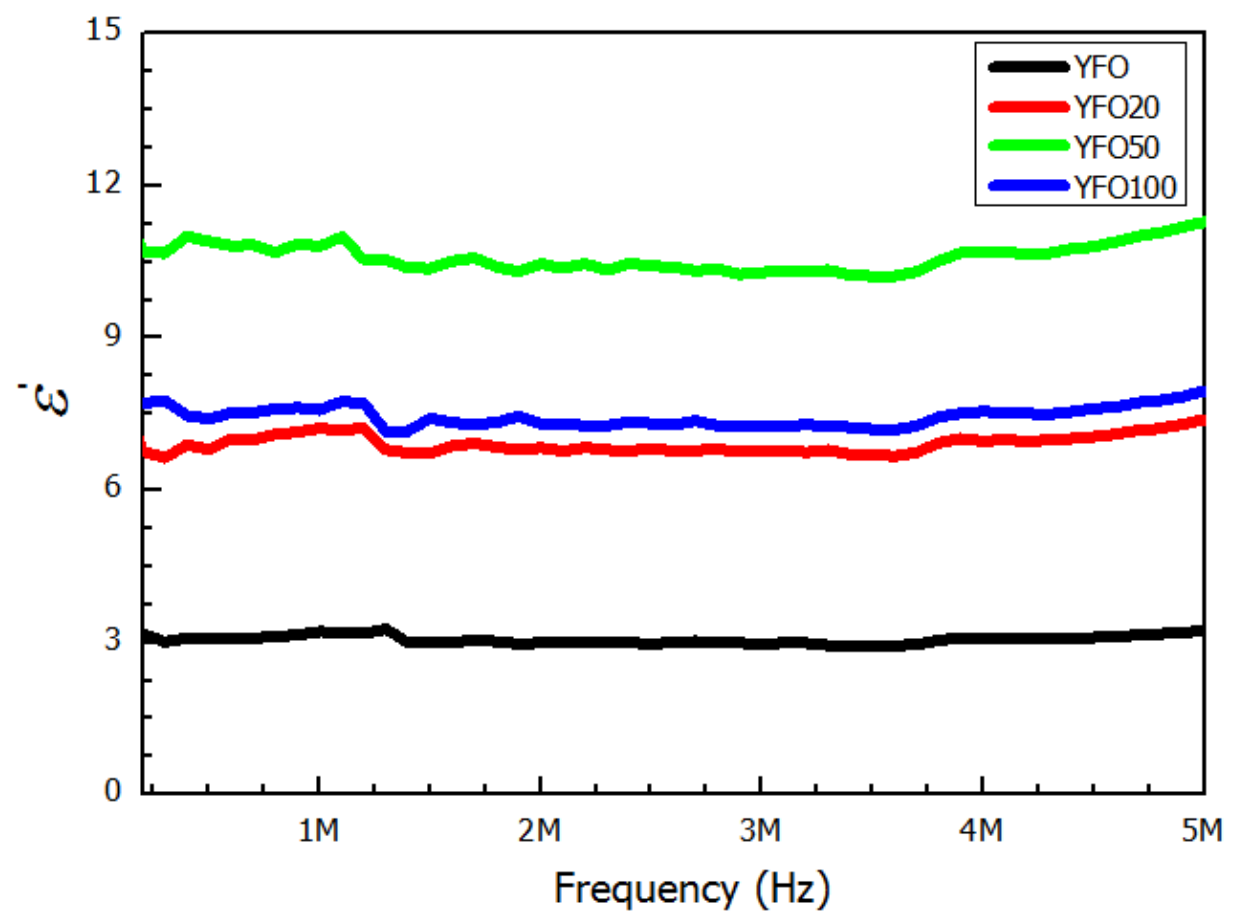

Figure 9. Relative permittivity as a function of frequency plots of the samples

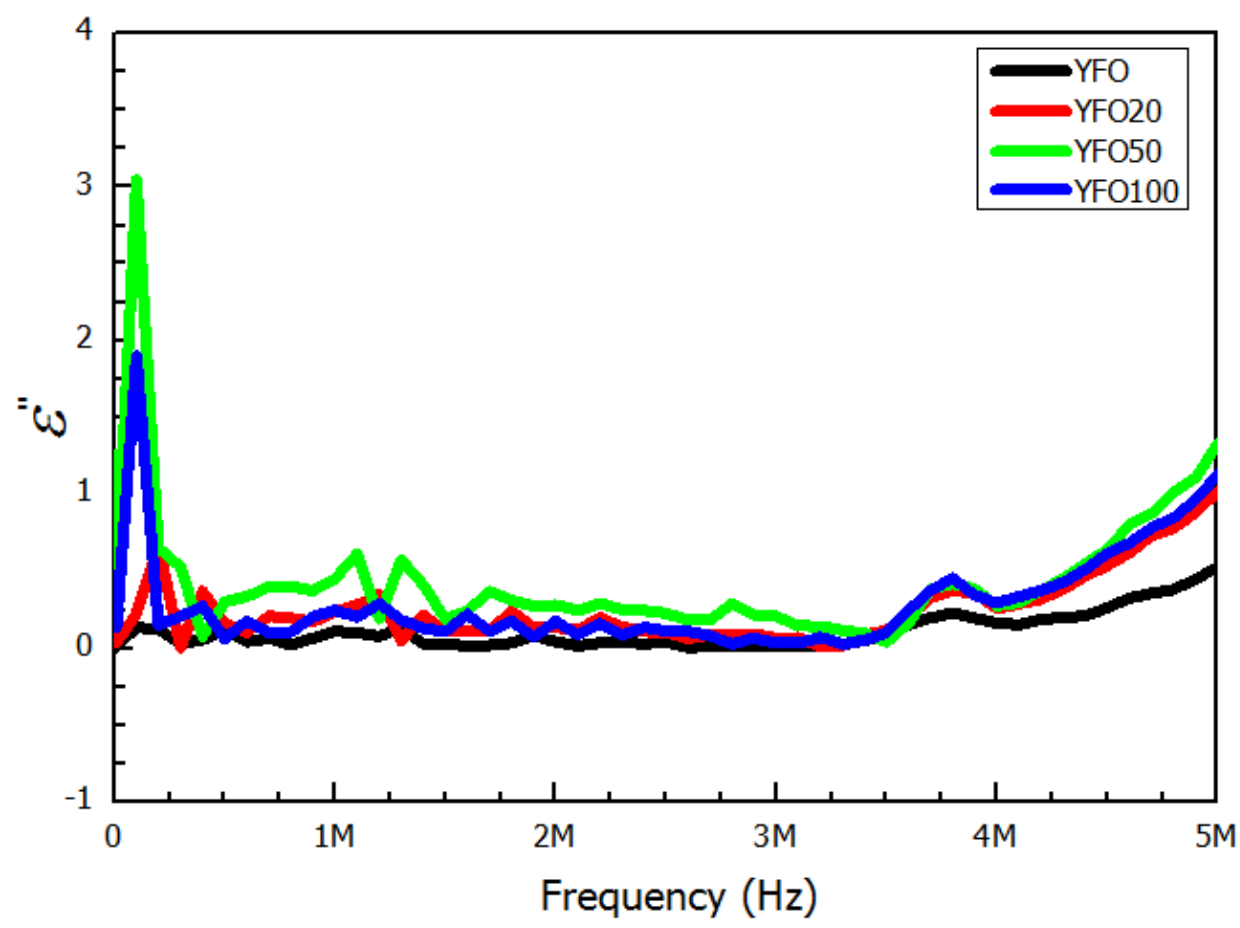

Figure 10. Dielectric loss as a function of frequency plots of the samples 


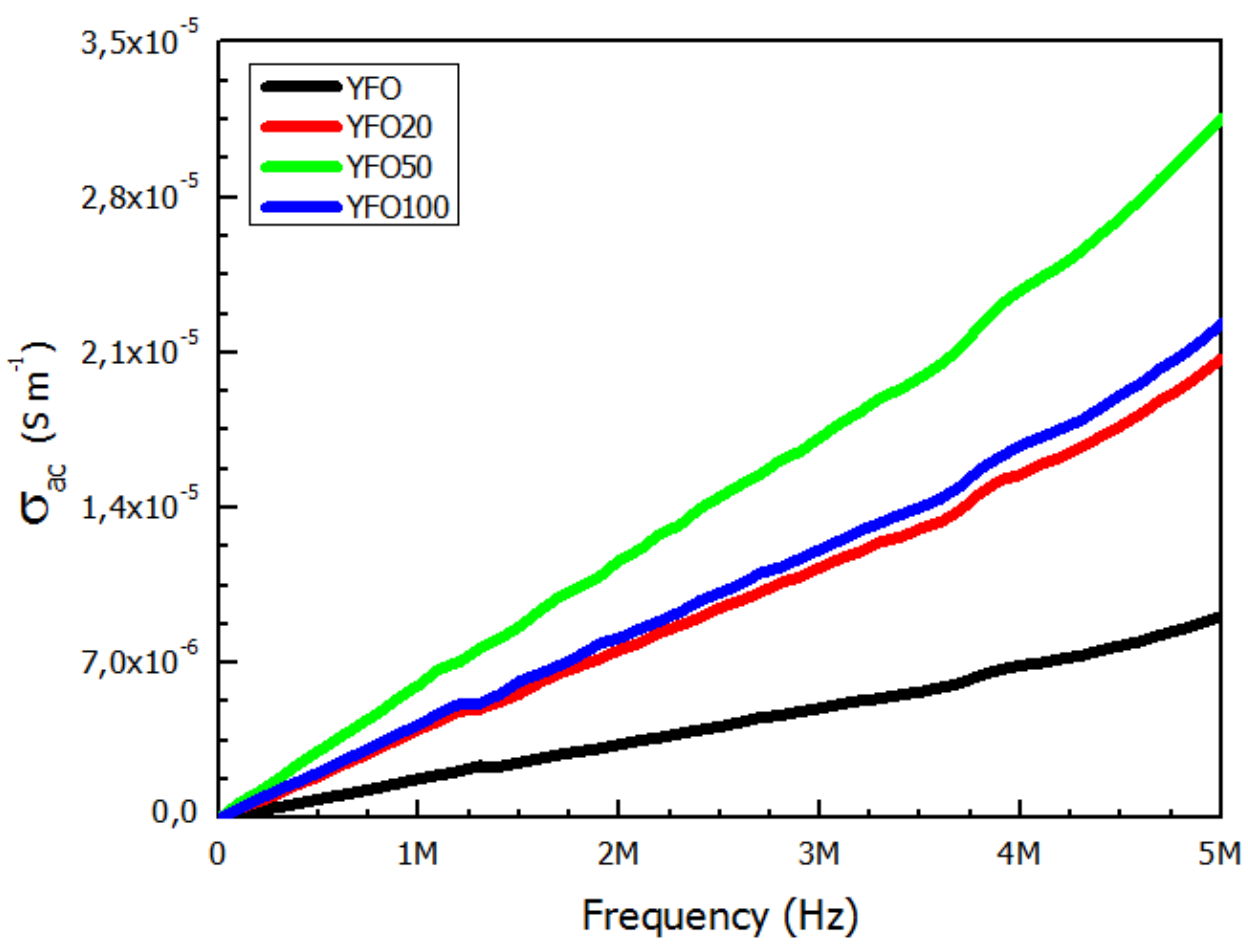

Figure 11. Alternating current conductivity vs. frequency plots of the samples

As can be seen from Figs. 9, 10 and 11, the relative permittivity $\left(\varepsilon^{\prime}\right)$, dielectric loss $\left(\varepsilon^{\prime \prime}\right)$ and alternating current conductivity $\left(\sigma_{a c}\right)$ are significantly affected by graphene oxide content, respectively. While the values of $\varepsilon^{\prime}$ and $\varepsilon^{\prime \prime}$ decrease with increasing of frequency, the $\sigma_{a c}$ increases linearly, for each sample. In brief, graphene oxide-doping into $\mathrm{YFeO}_{3}$ affects its dielectric properties and alternating current conductivity values. The relative permittivity value for each sample decreases at the higher frequencies in comparison to the lower ones since the contribution of the dipolar polarization is small at the higher frequencies because of the inertia of the molecules and ions. At the same time, the orientation of dipoles cannot adapt to the higher applied alternating fields, and this leads to the dielectric loss. The increase in the dielectric permittivity with the different graphene oxide-amount can be a sign of a percolation transition from an insulator to conductor.

The relative permittivity values of the nano electroceramic samples at different frequencies were given in Table 3.

Table 3. The relative permittivity values of the samples at different frequencies

\begin{tabular}{|c|c|c|c|c|c|c|c|c|c|}
\hline \multicolumn{10}{|c|}{$\varepsilon^{\prime}$} \\
\hline & $\varepsilon^{\prime} 1 \mathrm{kHz}$ & $\varepsilon^{\prime} 10 \mathrm{kHz}$ & $\varepsilon^{\prime} 100 \mathrm{kHz}$ & $\varepsilon^{\prime} 500 \mathrm{kHz}$ & $\varepsilon^{\prime} 1 \mathrm{MHz}$ & $\varepsilon_{2 \mathrm{MHz}}^{\prime}$ & $\varepsilon^{\prime} 3 \mathrm{MHz}$ & $\varepsilon^{\prime} 4 \mathrm{MHz}$ & $\varepsilon_{5 \mathrm{MHz}}^{\prime}$ \\
\hline YFO & 3,161 & 1,459 & 3,597 & 3,090 & 3,213 & 2,990 & 2,970 & 3,095 & 3,240 \\
\hline YFO20 & 7,330 & 3,349 & 8,037 & 6,797 & 7,219 & 6,833 & 6,776 & 6,966 & 7,391 \\
\hline YFO50 & 13,039 & 6,284 & 11,767 & 10,897 & 10,804 & 10,457 & 10,288 & 10,698 & 11,283 \\
\hline YFO100 & 8,575 & 3,349 & 7,400 & 7,406 & 7,580 & 7,307 & 7,263 & 7,551 & 7,957 \\
\hline
\end{tabular}


In order to determine the temperature-dependent variation of the produced undoped and graphene oxide-doped nano electroceramics and their electrical transmission mechanism, the temperaturedependent conductivity curves were used. The conductivity curves were analyzed using the equation known as Arrhenius equation [19, 20, 24, 28, 29,37] :

$$
\sigma_{d c}=\sigma_{0} \cdot \exp \left(\frac{\Delta E_{A}}{k T}\right)
$$

In Equation 7, $\sigma_{o}$; is the exponential function, $k$; Boltzmann constant and $E_{a}$ represents the activation energy. In the light of the data, $\ln \sigma-1000 / T$ change graphs were drawn for all samples and activation energies corresponding to the donor level were calculated.

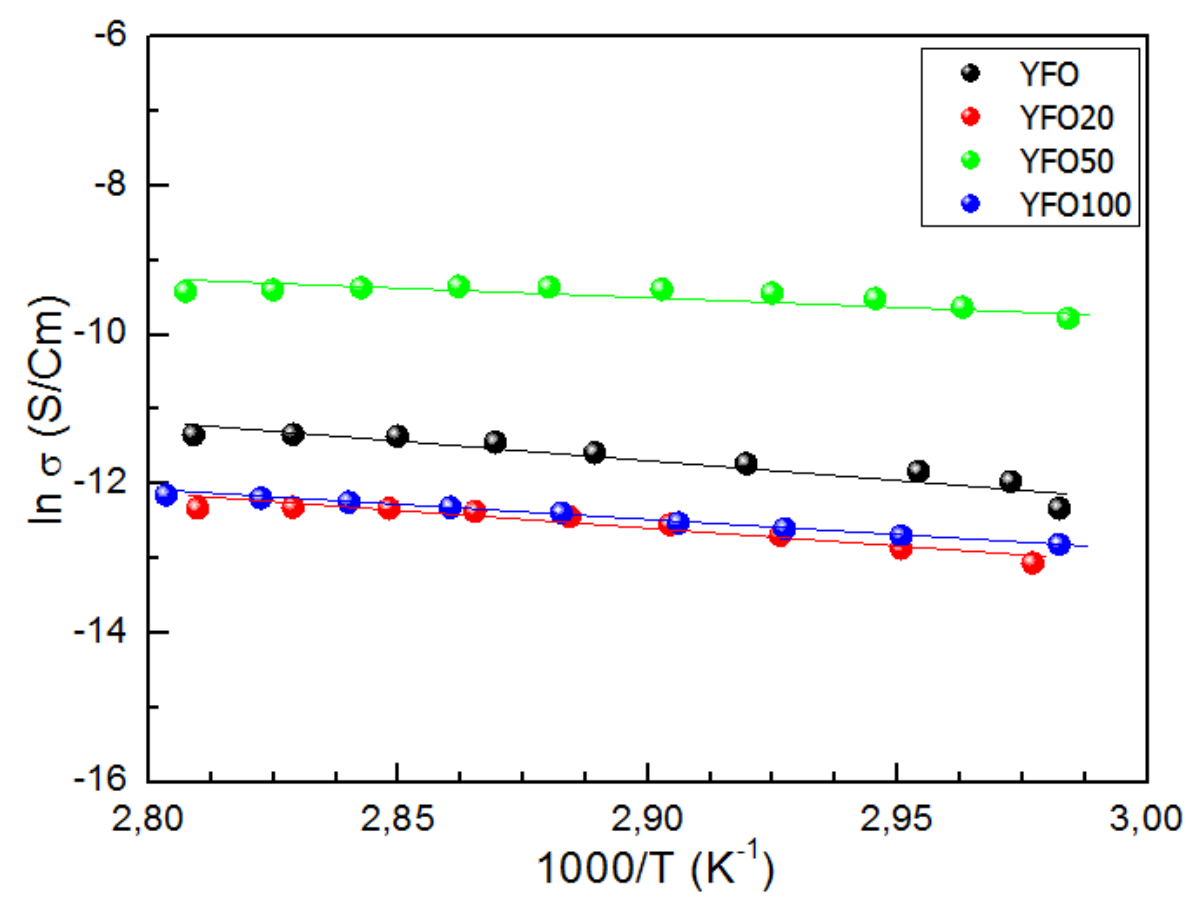

Figure 12. Temperature dependence of $D C$ electrical conductivity of the yttrium ferrite samples

Fig.12. shows $\ln \sigma-1000 / T$ graph of the samples. As seen in Fig.12., electrical conductivity of the samples changed as the amount of graphene oxide dopant changed. The highest conductivity value was observed in YFO50 sample. It was also clearly seen that as the temperature increased, the conductivity increased. For all the samples, a single conductivity mechanism occurred in the measured temperature range. This conductivity mechanism formed by the thermal excitation of the carrier loads. As the temperature increased, the electrons were thermally stimulated to the conductivity band from the donor levels. With increasing temperature, more load carrier contributed to the electrical conductivity by exceeding the activation energy barrier. The activation energy of the samples was calculated from the slope of the lines in the graph and was given in Table 2. When the values in Table 2 were examined, activation energies decreased in parallel with the increasing graphene oxide ratio. YFO100 sample had the lowest activation energy value. In addition, the conductivity values of the samples at room temperature changed based on the graphene oxide dopant. Table 2 shows the conductivity values of the samples at room temperature. 


\section{Discussion}

Undoped and different mass ratio graphene oxide doped $\mathrm{YFeO}_{3}$ based nanocomposite samples were prepared via hydrothermal method. Structural, morphological, chemical, optical and electrical properties of the samples were investigated. All of the results obtained from characterization show a change with graphene oxide contribution. As a result, in this study is especially important in terms of, nanoceramic semiconducting materials, which have an important place in technological applications, can be produced especially at low cost and easily and also offering the possibility to dope of graphene oxide, which is characterized as the superior feature material of our time. In addition, this article is an important guide for future studies on researching of physical and chemical properties of $\mathrm{YFeO}_{3}$ based organic semiconductors with doping different elements and exploring the potential for use in advanced electronic applications.

\section{References :}

[1]. Aydin, H.; El-Nasser, H. M.; Aydin, C.; Al-Ghamdi, A. A.; Yakuphanoglu, F. Synthesis and characterization of nanostructured undoped and Sn-doped $\mathrm{ZnO}$ thin films via sol-gel approach. Applied Surface Science, 350, (2015), pp.109-114.

[2] . Ahmad, T.; Lone, I. H.; Ansari, S. G.; Ahmed, J.; Ahamad, T.; Alshehri, S. M. Multifunctional properties and applications of yttrium ferrite nanoparticles prepared by citrate precursor route. Materials \& Design, 126, (2017), pp. 331-338.

[3] . Zhang, C.; Wang, Z.; Yan, H.; Wang, X.; Kang, D.; Li, L. Structural and magnetic properties in $\mathrm{YFe} 0.8 \mathrm{Mn} 0.2 \mathrm{O} 3$ ceramics. Materials Letters, 136, (2014), pp. 15-17.

[4]. Zhang, Y.; Yang, J.; Xu, J.; Gao, Q.; Hong, Z. Controllable synthesis of hexagonal and orthorhombic $\mathrm{YFeO} 3$ and their visible-light photocatalytic activities. Materials Letters, 81, (2012), pp. 1-4.

[5]. Shen, T.; Hu, C.; Yang, W. L.; Liu, H. C.; Wei, X. L. Theoretical investigation of magnetic, electronic and optical properties of orthorhombic YFeO3: A first-principle study. Materials Science in Semiconductor Processing, 34, (2015), pp. 114-120.

[6] . Ding, J.; Lü, X.; Shu, H.; Xie, J.; Zhang, H. Microwave-assisted synthesis of perovskite ReFeO3 (Re: La, Sm, Eu, Gd) photocatalyst. Materials Science and Engineering: $B$,171,(2010), pp. 3134.

[7]. Grabowska, E. Selected perovskite oxides: Characterization, preparation and photocatalytic properties-A review. Applied Catalysis B: Environmental, 186, (2016) , pp. 97-126.

[8] . Racu, A. V.; Ursu, D. H.; Kuliukova, O. V.; Logofatu, C.; Leca, A.; Miclau, M. Direct low temperature hydrothermal synthesis of $\mathrm{YFeO} 3$ microcrystals. Materials Letters, 140, (2015) ,pp.107-110.

[9] . Jabbarzare, S.; Abdellahi, M.; Ghayour, H.; Chami, A.; Hejazian, S. Mechanochemically assisted synthesis of yttrium ferrite ceramic and its visible light photocatalytic and magnetic properties. Journal of Alloys and Compounds, 688, (2014), pp. 1125-1130.

[10] . Stevens, F.; Cloots, R.; Poelman, D.; Vertruyen, B.; Henrist, C. Low temperature crystallization of yttrium orthoferrite by organic acid-assisted sol-gel synthesis. Materials Letters, 114, (2014), pp. 136-139. 
[11]. Zhang, Y.; Feng, J.; Xu, J.; Chen, G.; Hong, Z. Solvothermal Synthesis and Visible-Light Driven Photocatalytic Properties of YFeO3 Nanoparticles. Integrated Ferroelectrics, 151, (2014), pp. $108-115$.

[12] . Cho, Y. S.; Burdick, V. L.; Amarakoon, V. R. Hydrothermal preparation and morphology characteristics of Y3Fe5O12. Journal of the American Ceramic Society, 80, (1997), pp. 16051608.

[13] - Al-Hazmi, F. S.; Al-Ghamdi, A. A.; Bronstein, L. M.; Memesh, L. S.; Shokr, F. S.; Hafez, M. The influence of sintering temperature on the structure, optical and magnetic properties of Yttrium iron oxide $\mathrm{YFeO} 3$ prepared via $\mathrm{L} \alpha$-alanine assisted combustion method. Ceramics International, 43, (2017), pp. 8133-8138.

[14] . Lü, X.; Xie, J.; Shu, H.; Liu, J.; Yin, C.; Lin, J. Microwave-assisted synthesis of nanocrystalline YFeO3 and study of its photoactivity. Materials Science and Engineering: B, 138, (2007), pp. 289-292.

[15] . Aydin, C.; El-Nasser, H. M.; Yakuphanoglu, F.; Yahia, I. S.; Aksoy, M. Nanopowder synthesis of aluminum doped cadmium oxide via sol-gel calcination processing. Journal of Alloys and Compounds , 509, (2011), pp. 854-858.

[16] . Aydin, C.; Al-Hartomy, O. A.; Al-Ghamdi, A. A.; Al-Hazmi, F.; Yahia, I. S.; El-Tantawy, F.; Yakuphanoglu, F. Controlling of crystal size and optical band gap of $\mathrm{CdO}$ nanopowder semiconductors by low and high Fe contents. Journal of Electroceramics, 29, (2012), pp. 155 162.

[17]. Aydin, C.; Mansour, S. A.; Alahmed, Z. A.; Yakuphanoglu, F. Structural and optical characterization of sol-gel derived boron doped Fe2O3 nanostructured films. Journal of Sol-Gel Science and Technology, 62, (2012), pp. 397-403.

[18] . Aydin, H.; Aydin, C.; Al-Ghamdi, A. A.; Farooq, W. A.; Yakuphanoglu, F. Refractive index dispersion properties of $\mathrm{Cr}$-doped $\mathrm{ZnO}$ thin films by sol-gel spin coating method. Optik, 127, (2016), pp. 1879-1883.

[19] - Aydin, C.; Khusayfan, N. M.; Al-Ghamdi, A. A.; El-Tantawy, F.; Farooq, W. A.; Yakuphanoglu, F. Facile synthesis, electrical and optical properties of $\mathrm{Cu}$-doped $\mathrm{GaN}$ nanorods by sol-gel technique. Journal of Sol-Gel Science and Technology, 78, (2016) pp. 68-75.

[20] . Aydin, C.; Benhaliliba, M.; Al-Ghamdi, A. A.; Gafer, Z. H.; El-Tantawy, F.; Yakuphanoglu, F. Determination of optical band gap of $\mathrm{ZnO}: \mathrm{ZnAl} 2 \mathrm{O} 4$ composite semiconductor nanopowder materials by optical reflectance method. Journal of Electroceramics, 31, (2013), pp. 265-270.

[21] . Aydin, H.; Mansour, S. A.; Aydin, C.; Al-Ghamdi, A. A.; Al-Hartomy, O. A.; El-Tantawy, F.; Yakuphanoglu, F. Optical properties of nanostructure boron doped NiO thin films. Journal of SolGel Science and Technology, 64, (2012), pp. 728-733.

[22] . Orhan, A.; Aydin, C.; Aydin, H.; Al-Ghamdi, A. A.; El-Tantawy, F.; Yakuphanoglu, F. Synthesis and optical properties of iron doped gallium nitride nanostructures by sol gel method. Microsystem Technologies-Micro-and Nanosystems-Information Storage and Processing Systems, 21, (2015) pp. 1219-1224.

[23] . Benhaliliba, M.; Benouis, C. E.; Yakuphanoglu, F.; Tiburcio-Silver, A.; Aydin, C.; Hamzaoui, S.; Mouffak, Z. Detailed investigation of submicrometer-sized grains of chemically sprayed (Sn1xAlx, O-2) $(0<=\mathrm{x}<=0.085)$ thin films. Journal of Alloys and Compounds , 527, (2015), pp. 4047. 
[24] . Guler, O.; Guler, S. H.; Yo, F.; Aydin, H.; Aydin, C.; El-Tantawy, F.; Duraia, E. M.; Fouda, A. N. Electrical and Optical Properties of Carbon Nanotube Hybrid Zinc Oxide Nanocomposites Prepared by Ball Mill Technique. Fullerenes Nanotubes and Carbon Nanostructures, 23, (2015) pp. 865-869.

[25] . Wang, M.; Wang, T.; Song, S. H.; Ravi, M.; Liu, R. C.; Ji, S. S. Effect of calcination temperature on structural, magnetic and optical properties of multiferroic $\mathrm{YFeO} 3$ nanopowders synthesized by a low temperature solid-state reaction. Ceramics International , 43, (2017), pp. 10270-10276.

[26] . Kaygili, O.; Dorozhkin, S. V.; Ates, T.; Canan Gursoy, N.; Keser, S.; Yakuphanoglu, F.; Birkan Selçuk, A. Structural and dielectric properties of yttrium-substituted hydroxyapatites. Materials Science and Engineering: C , 47, (2015), pp. 333-338.

[27] . Kaygili, O.; Tatar, C.; Yakuphanoglu, F. Structural and dielectrical properties of Mg3-Ca3(PO4)2 bioceramics obtained from hydroxyapatite by sol-gel method. Ceramics International, 38, (2012), pp. 5713-5722.

[28] . Kaygili, O.; Keser, S.; Ates, T.; Yakuphanoglu, F. Synthesis and characterization of lithium calcium phosphate ceramics. Ceramics International , 39, (2013), pp. 7779-7785.

[29] . Aydin, C.; Abd El-sadek, M. S.; Zheng, K. B.; Yahia, I. S.; Yakuphanoglu, F. Synthesis, diffused reflectance and electrical properties of nanocrystalline $\mathrm{Fe}$-doped $\mathrm{ZnO}$ via sol-gel calcination technique. Optics and Laser Technology, 48, (2013), pp. 447-452.

[30] . Aydın, C. Synthesis of SnO2:rGO nanocomposites by the microwave-assisted hydrothermal method and change of the morphology, structural, optical and electrical properties. Journal of Alloys and Compounds, 771, (2019), pp. 964-972.

[31] . Aydin, C. Synthesis of Pd:ZnO nanofibers and their optical characterization dependent on modified morphological properties. Journal of Alloys and Compounds, 777, (2019), pp. 145-151.

[32] . Aydın, H.; Yakuphanoglu, F.; Aydın, C. Al-doped ZnO as a multifunctional nanomaterial: Structural, morphological, optical and low-temperature gas sensing properties. Journal of Alloys and Compounds, 773, (2019), pp. 802-811.

[33] . Aydin, H.; Gündüz, B.; Aydin, C. Surface morphology, spectroscopy, optical and conductivity properties of transparent poly(9-vinylcarbazole) thin films modified with graphene oxide. Synthetic Metals, 252, (2019), pp. 1-7.

[34] . Aydin, C.; Aydin, H.; Taskin, M.; Yakuphanoglu, F. A Novel Study: The Effect of Graphene Oxide on the Morphology, Crystal Structure, Optical and Electrical Properties of Lanthanum Ferrite Based Nano Electroceramics Synthesized by Hydrothermal Method. Journal of Nanoscience and Nanotechnology, 19, (2019), pp. 2547-2555.

[35] . Aydin, C. The functionalization of morphological, structural and optical properties of Fe doped $\mathrm{SnO} 2$ nanocrystals synthesized by the sol-gel method. Journal of Materials Science: Materials in Electronics, 29, (2018), pp. 20087-20096.

[36] . Aydin, C. Tin Oxide Based Nano Electroceramics Obtained from Sol\&\#8211;Gel Process: The Modified of the Structural and Opto-Electrical Properties with the Al Doping. Journal of Nanoelectronics and Optoelectronics, 13, (2018), pp. 1460-1467.

[37]. Aydın, C. Variation of structural and electrical properties of gallium nitride-based nanomaterials with nickel dopant at different atomic ratios. Ceramics International, 44, (2018), pp.1747317478. 